\title{
"La Suisse ne doit pas suivre le chemin de la France»
}

\section{Julia Rippstein}

Rédactrice print et online

Près d'un tiers des médecins en Suisse viennent de l'étranger. Pourquoi ont-ils quitté leur pays? Quels obstacles ont-ils rencontrés? Que pensent-ils de notre système de santé? Nous tentons de répondre à ces questions dans la rubrique «Bonjour la Suisse». Dans ce numéro, Saholy Razafinarivo-Schoreisz, pédiatre, raconte comment elle est arrivée à Courroux (JU) en 2016, après avoir vécu à Madagascar, aux Etats-Unis et en France.

"A 46 ans, un ami médecin généraliste a fait un infarctus. Il a failli y laisser sa peau. Cela a été le déclic: nous n'allions pas mourir en exerçant notre métier.» Après dix-huit ans de pratique libérale en France, le Dr Saholy Razafinarivo-Schoreisz, pédiatre, et son mari, psychiatre, décident de quitter ce pays où les conditions de travail sont devenues «catastrophiques» pour les médecins. Manque de relève, surcharge de travail, patients agressifs, salaires misérables: la Franco-Malgache dépeint un tableau très sombre. Une situation toxique qui empoisonne le corps médical, voire le mène à commettre l'irréparable. «Il y a une épidémie de suicides chez les médecins de mon âge», affirme la pédiatre de 55 ans. Elle a elle-même vécu un "cauchemar» au point de mettre sa santé en danger. En 2010, après le départ à la retraite de deux pédiatres, dont son associé, qui n'ont pas trouvé de successeurs, elle se retrouve seule à gérer les patients. «Je rentrais chez moi pour faire à manger à

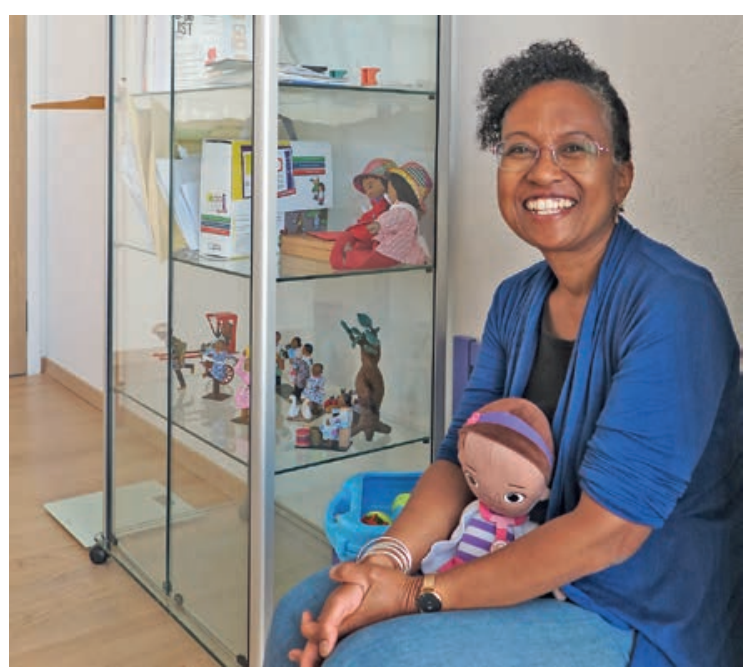

Saholy Schoreisz dans sa salle de consultation à Courroux. "Je ne porte jamais la blouse blanche!», dit-elle tout sourire. mes enfants, puis je retournais au cabinet pour régler la paperasse jusqu'à 22 heures. J'ai fini à l'hôpital, épuisée, sous perfusion", raconte-t-elle, encore marquée par cette période. Elle réduit alors son taux de travail, mais gagne tout juste pour vivre: «On ne va pas loin avec 15 patients par jour à 31 euros la consultation.»

\section{Du Canada au Jura}

L'espoir de pouvoir exercer son "métier-passion» dans de conditions meilleures renaît quand Saholy Razafinarivo-Schoreisz et son mari s'apprêtent à partir pour le Canada. A l'époque, leurs enfants y étudient. «Nos papiers étaient quasiment prêts, nous devions encore effectuer un stage», explique la pédiatre. Alors qu'ils sont sur le départ, les deux Français tombent sur une annonce d'une agence recrutant des praticiens pour des cabinets médicaux dans le Jura et changent leurs plans: en novembre 2016, après un an à visiter des cabinets, ils posent leurs valises à Courroux, un village à côté de Delémont. "L’endroit était idéal: nous pouvions chacun exercer en libéral, à trois kilomètres l'un de l'autre, aller au travail en vélo, vivre à la campagne. Le rêve! Et c'est plus pratique pour rentrer en France», dit Saholy Razafinarivo-Schoreisz en riant. La porte d'à côté, et pourtant, elle ignore tout de la Suisse.

Née à Madagascar, la pédiatre a toujours baigné dans un mélange de cultures et émigré à plusieurs reprises. "Je suis étrangère depuis 40 ans», résume-t-elle. Elle vit ses premières années aux Etats-Unis: son père y accomplit sa formation de chirurgien. Retour à Madagascar où elle passe son adolescence, «entourée de beaucoup d'enfants». Les études se feront outre-Atlantique, décide son père qui lui transmet le virus de la médecine. Elle suit un Bachelor en biologie, prérequis avant de pouvoir aller plus loin. Mais la concurrence est rude et elle n'est 
pas admise en médecine. Elle part donc en France pour réaliser son rêve de toujours: devenir pédiatre. Là, c'est le choc culturel: "Aux Etats-Unis, les étudiants sont appliqués et paient cher leurs études. En France, les cours ressemblaient à la foire d'empoigne alors que l'université est gratuite. Les jeunes Français ne réalisent pas leur chance. Je n'en croyais pas mes yeux!», se remémore avec amusement Saholy Razafinarivo-Schoreisz. Malgré tout, elle réussit ses études de médecine à Paris et passe en 1999 l'examen pour la spécialisation en pédiatrie à Poitiers.

\section{Agenda vide}

Bien qu'elle ait été habituée à «migrer», les débuts dans le Jura sont moins faciles que prévu. Si la pédiatre avait hâte de fuir la «misère médicale» de l'Hexagone, elle est toutefois rattrapée par cette réalité en Suisse. La faute à une pénurie de pédiatres très inégale dans le canton: «L'Ajoie et les Franches-Montagnes en sont presque dépourvus, alors que la vallée de Delémont est celle où se concentre la plupart des praticiens», explique-t-elle. Sans patients ni rentrée d'argent, Saholy Razafinarivo-Schoreisz postule auprès d'un hôpital en France voisine pour assurer le minimum vital et enchaîne les gardes de 24 heures pendant un an et demi. Une période "très stressante» qui la conforte dans l'idée qu'elle a bien fait de quitter ce pays. Aujourd'hui, la pédiatre travaille à $50 \%$ et gagne «déjà nette-

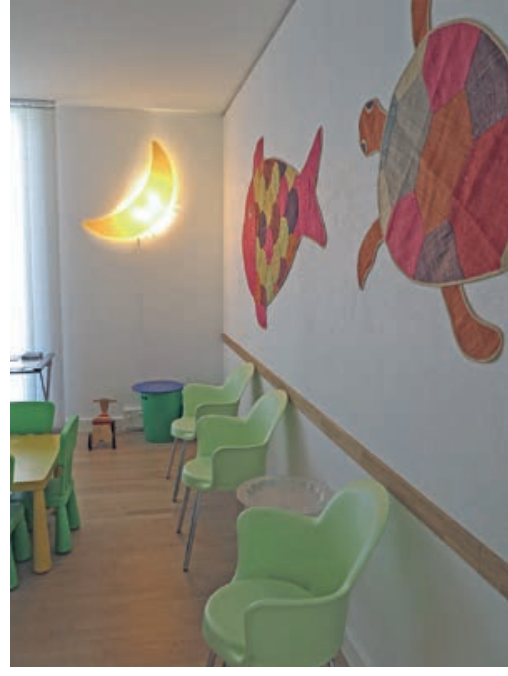

La salle d'attente est ornée de décorations malgaches. ment mieux». "Mais je ne serai jamais millionnaire», lâche-t-elle en riant. Elle peut ainsi se consacrer à son autre passion: l'écriture d'ouvrages pédiatriques pour les parents.

Et sa patientèle? «Très multiculturelle!» Saholy Razafinarivo-Schoreisz ne s'attendait pas à tant de mixité en Suisse: «Je parle toutes mes langues ici, même le japonais.» Parmi ses jeunes patients, des réfugiés aussi car elle collabore avec l'Association jurassienne d'accueil des migrants. «Les gens sont d'une gentillesse, poursuit-elle en se remémorant une anecdote. Lors de mes premières gardes, une maman est venue avec une boîte de chocolats, s'excusant de me «déranger». Je lui ai dit: «Vous ne me dérangez pas, je suis de garde!» Autre découverte "fascinante» pour la Franco-Malgache: le penchant des Suisses pour les remèdes de grandmère comme le thé de fenouil contre les maux de ventre été surprise de voir que des médicaments contre-indiqués en France sont prescrits en Suisse et vice-versa.

\section{Un bon salaire... mais un tas de paperasse}

Quant au système de santé suisse, elle apprécie que les médecins soient payés à leur «juste valeur». Un salaire qui garantit une qualité des soins et permet de passer du temps avec les patients: «En France, j'enchaînais les consultations, aujourd'hui j'en ai beaucoup moins mais je rentre chaque soir avec le sourire.» Par contre, Saholy Razafinarivo-Schoreisz bataille encore avec le système «compliqué» de facturation et la paperasse. Son autre bête noire: la diffculté de préserver le secret médical visà-vis des assurances.

Si les médecins en Suisse ont une situation enviée, cela pourrait changer. "Ce qui a lieu maintenant ici était actuel en France il y a vingt ans, s'alarme-t-elle. A l'époque, l'Etat a commencé à sabrer petit à petit les tarifs des prestations, une spécialité après l'autre, estimant que les médecins coûtaient trop cher.» Un signe avant-coureur de ce changement en Suisse? Les nombreux titres de journaux dénonçant le salaire mirobolant des médecins. La majorité est loin d'être pleine aux as, argue la doctoresse: "C'est un métier que l'on fait par passion.» Côté français, ce travail de sape a eu pour conséquence de dégoûter la relève et de faire de villes comme Paris des déserts médicaux. Sans compter les urgences qui saturent, les grèves et les patients qui, mécontents, s'en prennent physiquement au corps médical.

Ce qui est certain, c'est que Saholy RazafinarivoSchoreisz ne retournera pas en France. «En tout cas pas pour y exercer la médecine», s'empresse-t-elle d'ajouter. Elle se sent bien en Suisse, un pays qui l'a accueillie à bras ouverts et qu'elle veut mieux découvrir. Un conseil aux médecins étrangers? «Etre ouvert, curieux, faire l'effort de s'adapter sans attendre que le contraire ne se passe. Si s'expatrier n'est jamais facile, ce n'est pas que synonyme de perte, mais aussi d'enrichissement.»

\section{Crédit photos Julia Rippstein}

Pour notre rubrique «Bonjour la Suisse», nous recherchons des médecins étrangers intéressés à raconter ce qui les a motivés à venir en Suisse et comment ils y vivent. Vous pouvez nous faire part de votre intérêt par courriel: julia.rippstein[at]emh.ch 